\title{
G somentem \\ Pancreatic MR Imaging and Endocrine \\ Complications in Patients with Beta Thalassemia: A Single Center Experience
}

\section{Cihangir Sevimli}

Istanbul University Istanbul Faculty of Medicine: Istanbul Universitesi Istanbul Tip Fakultesi

Yasin Yilmaz ( $\nabla$ dryasinyilmaz@gmail.com )

Istanbul University Istanbul Faculty of Medicine: Istanbul Universitesi Istanbul Tip Fakultesi https://orcid.org/0000-0002-4811-5750

\section{Zuhal Bayramoglu}

Istanbul University Istanbul Faculty of Medicine: Istanbul Universitesi Istanbul Tip Fakultesi

\section{Rana Gunoz Comert}

Istanbul University Istanbul Faculty of Medicine: Istanbul Universitesi Istanbul Tip Fakultesi

Nurdan Gul

Istanbul University Istanbul Faculty of Medicine: Istanbul Universitesi Istanbul Tip Fakultesi

\section{Memduh Dursun}

Istanbul University Istanbul Faculty of Medicine: Istanbul Universitesi Istanbul Tip Fakultesi

\section{Zeynep Karakas}

Istanbul University Istanbul Faculty of Medicine: Istanbul Universitesi Istanbul Tip Fakultesi

\section{Research Article}

Keywords: Transfusion dependent thalassemia, Pancreas MRI, endocrinological complications

Posted Date: June 21st, 2021

DOl: https://doi.org/10.21203/rs.3.rs-283067/v1

License: (1) (1) This work is licensed under a Creative Commons Attribution 4.0 International License.

Read Full License

Version of Record: A version of this preprint was published at Clinical and Experimental Medicine on July 10th, 2021. See the published version at https://doi.org/10.1007/s10238-021-00735-7. 


\section{Abstract}

Iron deposition in various organs can cause endocrine complications in patients with transfusiondependent beta-thalassemia. The aim was to investigate the relationship between endocrine complications and pancreatic iron overload using magnetic resonance imaging (MRI). Forty patients with transfusion-dependent thalassemia (TDT) were enrolled in the study. The magnetic resonance imagings of the patients were performed using a 1.5 Tesla Philips MRI scanner. Two out of three patients had at least one clinical endocrine complication. The rate of iron deposition was $62.5 \%$ in liver, and $45 \%$ in pancreas tissue, and was $12.5 \%$ in heart tissue. Pancreatic T2* and hepatic T2* values were significantly positively correlated $(p=0.006)$. Pancreatic $T 2^{*}$ and ferritin were significantly negatively correlated $(p=$ $0.03)$. Cardiac $T 2 *$ values were negatively correlated with fasting blood glucose $(p=0.03)$. Patients with short stature had significantly higher cardiac iron burden (22.3 vs. $36.6 \mathrm{~T} 2 * \mathrm{~ms} ; \mathrm{p} 00.01)$ and patients with hypothyroidism had higher liver iron concentrations ( $9.9 \mathrm{vs} .6 .4 \mathrm{LIC} \mathrm{mg/g;} p=0.05$ ). The ferritin level of $841 \mathrm{ng} / \mathrm{mL}$, and liver iron concentration (LIC) value of $8.7 \mathrm{mg} / \mathrm{g}$ were detected as the threshold level for severe pancreatic iron burden (AUC 70\%, p:0.04, AUC 80\%, $p=0.002$, respectively). Moreover, males were found to have decreased pancreas $T 2 *$ values compared with the values in females (T2* 19.3 vs. 29.9, $p$ $=0.05$ ). Patients with higher ferritin levels over than $840 \mathrm{ng} / \mathrm{mL}$ should be closely monitored for pancreatic iron deposition, and patients with endocrine complications should be assessed in terms of cardiac iron burden.

\section{Introduction}

Transfusion-dependent thalassemia (TDT) requires regular blood transfusions, and the iron overload is unavoidable if chelation therapy is not suitable [1]. Iron burden in liver, heart, pancreas, and hypophysis can originate a complication spectrum.

Diabetes, hypogonadism, short stature, and osteoporosis were the commonly detected endocrine disorders among patients with thalassemia [2]. Awareness of complications, early monitoring of patients, and starting the necessary chelator may decrease the rate of endocrine comorbidities [3].

Iron can also deposit in extrahepatic organs such as heart and pancreas specifically in the form of nontransferrin-bound iron (NTBI) [4]. Therefore, these organs are also sensitive to chelation therapy [5]. Screening the association of iron burden in extrahepatic organs is one another way of evaluation for patients. Studies supporting these assumptions showed that iron overload in endocrine organs can have association with hepatic and cardiac functions $[6,7]$.

Therefore, the close follow-up of patients in terms of iron burden in extrahepatic organs (e.g. heart, pancreas) with magnetic resonance imaging (MRI) is important for the physicians. In the present study, we aimed to screen the endocrine comorbidities of TDT patients, and to investigate the relationship between comorbidities and iron overload in pancreas, liver, and heart. 


\section{Materials And Methods \\ Study Design}

This research was a cross-sectional study, which was conducted in Thalassemia Center of Istanbul Faculty of Medicine in Turkey. The transfusion dependent thalassemia patients who were routinely followed up in our center were asked to participate in the study. Volunteer participants underwent MR imaging between January 2018, and April 2018 in Radiology Department of Istanbul Faculty of Medicine. Participants

Forty patients (females 50\%) with TDT who had received regular transfusion (14 thalassemia intermedia, and 26 thalassemia major patients) were recruited in the study. Patients accepted to have MRI scans of the pancreas during routine scanning of the heart and liver.

All patients had received blood transfusion in every 3 to 4 weeks (the median transfusion number was 18 per year) to maintain the hemoglobin level between $9-10 \mathrm{~g} / \mathrm{dL}$. Forty percent of the patients' parents had consanguineous marriage.

Thirty (75\%) patients had received deferasirox (DFX), nine patients (23\%) had received deferiprone (DFP), and one patient used both DFP, and deferasirox. No problem was detected in adherence to chelation therapy. (Table 1). 
Table 1

Clinical and laboratory characteristics of the patients

\begin{tabular}{|ll|}
\hline Characteristics & Transfusion Dependent Thalassemia $(\mathbf{n}=40)$ \\
\hline Gender $(\mathrm{f})$ & $20(50 \%)$ \\
\hline Age & $32.1 \pm 10.6$ \\
\hline Disease duration \pm SD years & $30.3 \pm 10.5$ \\
mean \pm SD years & $(30)$ \\
(median) & \\
\hline Age of diagnosis & $22.5 \pm 26.3$ \\
mean \pm SD months & $(12)$ \\
(median) & \\
\hline Age of starting regular transfusion & $31.0 \pm 37.4$ \\
mean \pm SD months & $(12)$ \\
(median) & \\
\hline Age of starting iron chelation & $107.9 \pm 90.0$ \\
mean \pm SD months & $(84)$ \\
(median) & \\
\hline Age of splenectomy & $181.6 \pm 90.7$ \\
mean \pm SD months & $(168)$ \\
(median) & $(18)$ \\
\hline Transfusion number annually & \\
mean \pm SD & $22.0 \pm 3.1$ \\
(median) & \\
\hline Body mass index & \\
mean \pm SD kg/m ${ }^{2}$ & \\
\hline Splenectomy (yes) & \\
\hline
\end{tabular}




\begin{tabular}{|ll|}
\hline Characteristics & Transfusion Dependent Thalassemia $(\mathbf{n}=40)$ \\
\hline Chelation Therapy & $30(75 \%)$ \\
DFX & $9(23 \%)$ \\
DFP & $1(2 \%)$ \\
DFX + DFP & \\
Endocrine Complications & $20(50 \%)$ \\
Osteoporosis & $12(30 \%)$ \\
Hypogonadism & $9(22 \%)$ \\
Diabetes & $8(20 \%)$ \\
Hypothyroidism & $6(15 \%)$ \\
Short stature & \\
\hline
\end{tabular}


Table 2

The findings of MRI investigations of the patients

\begin{tabular}{|ll|}
\hline Characteristics & Parameters \\
\hline Ferritin & $1336.8 \pm 1039.1$ \\
(mean \pm SD ng/mL & $(987)$ \\
$<1000 \mathrm{ng} / \mathrm{ml}$ & $21(52 \%)$ \\
$1000-2000 \mathrm{ng} / \mathrm{ml}$ & $12(30 \%)$ \\
$>2000 \mathrm{ng} / \mathrm{ml}$ & $7(18 \%)$ \\
\hline Pancreas R2* & $121.7 \pm 168.1$ \\
mean $\pm \mathrm{SD} \mathrm{Hz}$ & $(41.6)$ \\
(median) & $22(55 \%)$ \\
$<48 \mathrm{~Hz}$ & $6(15 \%)$ \\
$48-100 \mathrm{~Hz}$ & $3(7.5 \%)$ \\
$100-150 \mathrm{~Hz}$ & $9(22.5 \%)$ \\
$>150 \mathrm{~Hz}$ & \\
\hline Pancreas T2* & $24.6 \pm 17.4$ \\
mean $\pm \mathrm{SD} \mathrm{ms}$ & $(24)$ \\
(median) & $18(45 \%)$ \\
$<21 \mathrm{~ms}$ & $22(55 \%)$ \\
$>21 \mathrm{~ms}$ & \\
\hline Cardiac T2* & $34.4 \pm 13.4$ \\
mean $\pm \mathrm{SD} \mathrm{ms}$ & $(36.8)$ \\
(median) & $4(10 \%)$ \\
$<10 \mathrm{~ms}$ & $1(2.5 \%)$ \\
$10-20 \mathrm{~ms}$ & $35(87.5 \%)$ \\
$>20 \mathrm{~ms}$ & \\
\hline & \\
\hline
\end{tabular}




\begin{tabular}{|ll|}
\hline Characteristics & Parameters \\
\hline Hepatic T2* & $6.2 \pm 6.3$ \\
mean \pm SD ms & $(3.1)$ \\
(median) & $4(10 \%)$ \\
$<1.4 \mathrm{~ms}$ & $21(52.5 \%)$ \\
$1.4-6.7 \mathrm{~ms}$ & $15(37.5 \%)$ \\
$>6.7 \mathrm{~ms}$ & \\
Liver Iron Concentration & $7.1 \pm 4.6$ \\
mean \pm SD mg/g & $(6.9)$ \\
(median) & \\
\hline
\end{tabular}

Table 3

Hepatic and cardiac iron burden of patients with pancreatic iron overload

\begin{tabular}{|lll|}
\hline Pancreas R2* level & Hepatic Iron Burden & Cardiac Iron Burden \\
\hline$>40 \mathrm{~Hz}$ & $76 \%$ & $19 \%$ \\
\hline$>50 \mathrm{~Hz}$ & $88 \%$ & $24 \%$ \\
\hline$>60 \mathrm{~Hz}$ & $88 \%$ & $25 \%$ \\
\hline$>70 \mathrm{~Hz}$ & $88 \%$ & $29 \%$ \\
\hline$>80 \mathrm{~Hz}$ & $92 \%$ & $33 \%$ \\
\hline$>90 \mathrm{~Hz}$ & $92 \%$ & $33 \%$ \\
\hline$>100 \mathrm{~Hz}$ & $92 \%$ & $33 \%$ \\
\hline $\begin{array}{l}\text { Among patients with pancreatic R2*>80 Hz, 92\% of patients had hepatic iron overload and } 33 \% \text { of } \\
\text { patients had cardiac iron overload }\end{array}$ \\
\hline
\end{tabular}

Cardiac iron overload was accepted as T2* value $<20 \mathrm{~ms}$ [8], hepatic iron overload was accepted as T2* $<6.7 \mathrm{~ms}$ [9], and pancreas iron overload was accepted as $\mathrm{T} 2^{\star}<21 \mathrm{~ms}$ or R2 ${ }^{\star}>48 \mathrm{~Hz}[10,13]$, some other studies accepted T2* level as $26 \mathrm{~ms}[11,12]$ - Pancreas R2* more than $150 \mathrm{~Hz}$ was accepted as moderate to severe pancreatic iron overload [6].

\section{Magnetic Resonance Imaging}

In this study, unenhanced upper abdomen MRI images were obtained using a Philips Achieva 1.5Tesla system (Achieva 1.5T A-series, Philips, Holland). The images were taken in supine position as the patients hold their breath. 
The imaging protocol consisted of the following sequences as coronal plane spectral attenuated inversion recovery (SPAIR), coronal plane T2W Turbo Spin Echo (TSE), axial plane T2W-TSE, and merged fast field echo (M-FFE), and dual fast field echo (DUAL-FFE) the sequence we use for the actual iron calculation. Phlips M-FFE is a T2 * weighted gradient echo sequence in which transverse magnetization is spoiled with long repetition time (TR). Gradient echoes obtained in different TE values in the M-FFE sequence are combined in a single image with a reconstruction algorithm.

The sections to be measured were obtained from the mid-hepatic level, the section where the vascular structures were not intensely monitored so that the liver was not affected by vascular flow artifacts. In the calculating program we used, the values obtained were averaged by placing three ROls at the level determined in the liver and pancreas as iron accumulation within the hepatic lobule and pancreas may not be homogeneous. To detect pancreatic iron, the sections where pancreas could be best evaluated were selected, and studied in the iron analysis program using the Wood method. The Wood method runs 16 T2*-weighted single-echo gradient echo sequences in a single-breath-hold with constant flip angle $\left(20^{\circ}\right)$, constant TR $(400 \mathrm{~ms})$, and increasing TE (range 8-19, delta-TE $\left.0.8 \mathrm{~ms}\right)$, field-of-view $400 \mathrm{~mm}$. The R2* was measured by inserting the observed data to a mono-exponential model with offset to develop a parametric map [14]. In the study, the Wood method was used to calculate the iron accumulation in the liver, and pancreas. T2* is the gradient echo equivalent of T2 in spin echo. The R2* value is the reciprocal of the $\mathrm{T}^{*}$ value $\left(\mathrm{R} 2^{\star}=1000 / \mathrm{T} 2^{\star}\right)$.

Additionally in dual echo chemical shift imaging in 1.5 T MRI, the signals are collected in the same TR interval as 2.3 and $4.6 \mathrm{~ms}$ and their multiples at two different echo times (short echo / out of phase, long echo / in phase). When the transverse magnetic vectors of the fat and water protons in the same voxel are in the same direction (in phase) additive (water + fat) signal and 180 degrees in the opposite direction (out of phase) decreasing (water - fat) signal is obtained. This method enables visual and quantitative measurement of steatosis. When measuring from the liver in patients with heterogeneously distributed hepatosteatosis, $\mathrm{ROI}$ was placed in areas where steatosis is not present by visual evaluation with the help of dual echo sequences.

However, it should be noted that hepatic fibrosis and inflammation may decrease the T2 shortening effect caused by iron by prolonging the $\mathrm{T} 2$ relaxation time. But, a similar limitation occurs in $\mathrm{T} 2$ relaxometry mapping, which is another measurement method because fibrosis prevents diffusion (14). Since fat is a complex molecule, the presence of steatosis accelerates T2 dephasing and affects T2 * measurement. The Wood method we used in our study is a limitation of our study, since it is not a method that simultaneously performs spectral fat sampling while measuring T2 (14).

Especially, considering that MRI examination is more competent in detecting moderate to severe fat (38), we have reduced this limitation by not including patients with visually evident hepatosteatosis in dual echo chemical shift examination.

\section{Endocrinologic evaluation}


Patients diagnosed as having endocrinologic complications were followed up in the endocrinology outpatient clinic, and the diagnosis was established in accordance with the clinical guidelines [15].

Diabetes mellitus was described as the fasting glucose over $126 \mathrm{mg} / \mathrm{dL}$ confirmed by repeated tests (at least two occasions) or any time blood sugar detected over $200 \mathrm{mg} / \mathrm{dL}$. Hypothyroidism was considered as the lack of free thyroxin (fT4) with high (primary) or low-to-normal thyroid-stimulating hormone (TSH) (secondary). Osteoporosis was considered with decreased bone mineral density (T score below - $2.5 \mathrm{SD}$ or Z score below - 2 SD), and fracture history. Hypogonadism was defined as the lack of secondary sex characters at age 13 years in girls and 14 years in boys. For gonadal development, laboratory confirmations were performed by an endocrinologist. Short stature was described as height measurement below - 2SD.

\section{Data analysis}

The Statistical Package for the Social Sciences(SPSS) 22 software was used in the statistical analyses. Student's t-test, the Mann- Whitney U test, correlation analysis, and receiver operating characteristics (ROC) curve analysis were used. $p<0.05$ was considered as significant.

Ethical approval

The study was approved by the Ethics Board of the Istanbul University (protocol no: 201821).

\section{Results}

The mean disease duration was $30.3 \pm 10.5$ years, and mean age at diagnosis was $22.5 \pm 26.3$ (median 12) months. The mean age of starting regular transfusion was $31.0 \pm 37.4$ (median 12) months, and the mean age of starting iron chelation was $107.9 \pm 90.0$ (median 84) months. The mean age of splenectomy was $181.6 \pm 90.7$ (median 168) months. Twenty-five (62\%) patients had undergone splenectomy. The median body mass index was $21 \mathrm{~kg} / \mathrm{m}^{2}$. The median age of first menstrual cycle was 16.5 years for girls.

One or more clinical endocrine complications were detected in $65 \%$ of the participants $(n=26)$. The frequency of complications was $50 \%$ for osteoporosis $(n=20), 30 \%$ for hypogonadism $(n=12), 22 \%$ for diabetes mellitus $(n=9), 20 \%$ for primary hypothyroidism $(n=8)$, and $15 \%$ for short stature $(n=6)$ (Table 1).

The mean serum ferritin level was $1336.8 \pm 1039.1 \mathrm{ng} / \mathrm{mL}$ (median 987). The serum ferritin level was detected lower than $1000 \mathrm{ng} / \mathrm{mL}$ in half of the patients. Ferritin levels were slightly higher in males (1405 vs. $1268 \mathrm{ng} / \mathrm{mL}, \mathrm{p}=0.68$ ) compared with the levels in females.

The pancreas MRI showed the mean R2* value as $121.7 \pm 168.1$ (median 41.6) $\mathrm{Hz}$, and the mean T2* value as $24.6 \pm 17.4$ (median 24.0 ) $\mathrm{ms}$ (Table 2). Eighteen patients (45\%) had iron overload in the pancreas, and nine (22.5\%) patients had moderate to severe pancreas iron burden ( $R 2 *>150 \mathrm{~Hz})$. Above the pancreatic R2* level of $80 \mathrm{~Hz}$, the percentage of patients with hepatic and cardiac iron overload reached a plateau (Table 3). Patients with endocrine complications had nonsignificantly lower mean 
pancreas T2* values compared to the values in patients with no endocrine complications ( 21.9 vs. 29.6 $\mathrm{ms}, \mathrm{p}=0.18)$. The mean pancreas $\mathrm{T} 2^{\star}$ values of patients with diabetes was insignificant compared with the values in patients without diabetes ( $21.8 \mathrm{vs} .25 .4, p=0.59)$. No significant correlations were detected between pancreatic MR values with fructosamine, fasting blood glucose, insulin, C-peptides, and HOMAIR indexes $(p>0.05)$.

Ferritin level was positively correlated with pancreas $R 2 *(r=0.42, p=0.006)$ and negatively correlated with pancreas $T 2^{\star}(r=-0.33, p=0.03)$, and hepatic T2* value $(r=-0.35, p=0.02)$. The pancreas $T 2^{*}$ value was positively correlated with hepatic $T 2 *(r=0.42, p=0.006)$ and negatively correlated with liver iron concentration $(r=-0.37, p=0.01)$. The pancreatic $T 2^{*}$ value was significantly lower in males (19.3 vs. $29.9, p=0.05)$, however, the rate of pancreatic iron overload showed no difference in accordance with sex $(p=0.52)$. However, ferritin, and hepatic and cardiac T2* values did not differ by sex.

The cardiac T2* value was negatively correlated with fasting blood glucose $(r=-0.33, p=0.03)$. Ferritin level was positively correlated with fasting blood glucose $(r=0.37, p=0.02)$ and $\operatorname{HOMA-IR}(r=0.32, p=$ 0.04).

Patients with short stature had significantly lower cardiac T2* $(22.3$ vs. $36.6 \mathrm{~ms}, \mathrm{p}=0.01)$ values. Patients with hypothyroidism had higher liver iron concentrations ( 9.9 vs. $6.4 \mathrm{LIC} \mathrm{mg/g;} \mathrm{p}=0.05$ ). Fifty five percent of the patients $(n=18)$ had no pancreatic iron overload (i.e. pancreatic T2* $>21 \mathrm{~ms}), 87.5 \%$ of the patients $(n=35)$ had no cardiac iron burden (i.e. cardiac $\left.T 2^{\star}>20 \mathrm{~ms}\right)$, and $37.5 \%$ of the patients $(n=$ 15) were free of hepatic iron burden (i.e. hepatic T2* $>6.7 \mathrm{~ms}$ ) (Fig. 1).

The serum ferritin level of $841 \mathrm{ng} / \mathrm{mL}$ was detected as the threshold level for liver iron deposition with $80 \%$ sensitivity and $80 \%$ specificity $(p=0.002, A U C=0.80)$ and was determined as the threshold level for severe pancreatic iron burden with $83 \%$ sensitivity and $54 \%$ specificity $(p=0.04, A U C=0.70)$. Above the ferritin level of $841 \mathrm{ng} / \mathrm{mL}$, the risk of severe pancreatic iron overload increased 5.7-fold [odds ratio (OR) $5.7 ; 95 \% \mathrm{Cl}: 1.06-31.27]$. The value of $8.7 \mathrm{mg} / \mathrm{g}$ for LIC was detected as the threshold level for severe pancreatic iron deposition ( $83 \%$ sensitivity and $78 \%$ specificity; $p=0.002, A U C=0.80$ ). Above the LIC level of $8.7 \mathrm{mg} / \mathrm{g}$, the risk of severe pancreatic iron overload increased 12.5 -fold (OR 12.5; $95 \% \mathrm{Cl}$ : 2.2270.18).

No significant correlation was found between pancreas iron deposition, with chelation type, and age.

\section{Discussion}

In this study, we showed that at least one clinical endocrine complication was detected in two out of three TDT patients. The rate of iron deposition was $62.5 \%$ in liver, and $45 \%$ in pancreas tissue, and was $12.5 \%$ in heart tissue. The serum ferritin level of $841 \mathrm{ng} / \mathrm{mL}$ was shown as a threshold of iron deposition for liver, and for severe pancreatic iron burden. The pancreatic R2* value of $80 \mathrm{~Hz}$ was regarded as the threshold level for further cardiac and hepatic iron evaluation. Patients with short stature showed more 
iron load in the heart, and the more iron in heart resulted with the higher fasting blood glucose in serum. This result may suggest that patients with iron burden in the heart are at risk for diabetes.

As chelation therapy increased the life span of thalassemia patients, previously unminded complications foremost the endocrinal complications gained importance (16-20). The hypothetical reality of these complications is based on severe iron burden in endocrine organs, which disturbs their synthesis function. From the clinical practice point of view, the unfavorable effect of ferritin on pubertal development can be minimized by the use of appropriate chelation therapy in proper time [21, 22]. A very recent study showed the good effect of appropriate chelation therapy on endocrinologic complications in children with thalassemia [23].

We found that almost half of the patients had pancreatic iron overload. Noetzli et al. [6] and Au et al. [10] found the pancreatic iron load as $80 \%$, Kolnagou et al. [24] found as $85 \%$, de Assis et al. [13] found as $86 \%$, and Meloni et al. [12] found a rate of $93 \%$ in patients with thalassemia. Our finding of a more favorable rate is debatable because half of the patients had a higher serum ferritin level over 1000 $\mathrm{ng} / \mathrm{mL}$. Even if we had chosen the cut-off value as T2* $26 \mathrm{~ms}$, the iron overload rate in pancreas would be $50 \%$. Furthermore, thalassemia major population and the $\mathrm{T} 2 *$ methodology might be the other possible explanations as it is dependent to the sequence, the software analysis, and the single scanner. On the other hand, our patients were closely followed up using proper chelation therapy.

One of the clinical benefits of MR imaging is that it is more accurate than serum analysis of ferritin in these patients. Previously, a serum ferritin level of over $2500 \mathrm{ng} / \mathrm{mL}$ was accepted as a risk factor for mortality in patients with thalassemia [7], currently, a serum ferritin level of $841 \mathrm{ng} / \mathrm{mL}$ was detected as the threshold level for liver iron burden and severe pancreatic iron burden using MR imaging. Moreover, a pancreatic R2* value of $80 \mathrm{~Hz}$ should alert us to cardiac and hepatic iron evaluation. Similar value of R2* $(100 \mathrm{~Hz})$ was shown by Noetzli et al. [6]. The relationship between MR results of organs can clearly show the systemic iron burden, and inform about the following complications that will occur.

Males were found to have a decreased T2* value in the pancreas in the present study. Moreover, we found a decreased level of insulin, and increased level of fructosamine in males compared with the levels in females ( $p=0.06$ and $p=0.05$, respectively). We found no supporting data in the literature. No sex difference was detected between the diabetic patients. Disease duration, age and body mass index showed no difference between male and females. We found no helpful cause for this discrepancy. Pancreatic iron overload causes decreased insulin secretion and thus precipitating diabetes in patients with thalassemia. Insulin resistance, and insulin deficiency together revealed the complexity of diabetes in thalassemia $[25,26]$. Thus, pancreatic and liver iron overload is shown to be associated with diabetes in patients with thalassemia [27]. Seventy percent of male patients had hepatic iron overload while 55\% of female patients had hepatic iron burden. This finding illustrates that male patients with TDT should be closely followed up in terms of diabetes.

Using MR imaging, recent studies revealed the association between heart and liver with other organs in terms of iron overload [28-30]. We showed that the rate of hepatic (80\%) and pancreatic (80\%) iron 
overload were significantly higher among patients with cardiac iron overload. Moreover, the rate of hepatic (84\%) and cardiac (22\%) iron deposition were also increased among patients with pancreatic iron overload. This finding may be useful in the approach to patients with cardiac, and pancreatic iron burden. A very recent multicenter study with more than 1000 thalassemia major patients showed that patients with cardiac fibrosis and cardiac complications had significantly lower pancreas T2* level [37].

Researchers concluded that pancreatic iron overload is an indicator for cardiac iron burden. Cardiac iron overload can be managed through more aggressive treatment such as a combined chelator because chelation therapy acts on hepatic and extrahepatic tissue and extrahepatic organs release iron very slowly out of the body [31, 35], but also deferiprone in monotherapy [36].

The cardiac iron burden was found associated with diabetes in the recent literature [32]. We found consistent with the literature that the cardiac T2* value was negatively correlated with fasting blood glucose. Similarly, patients with diabetes and thalassemia can develop myocardial fibrosis. Therefore, disorders in carbonhydrate metabolism should be screened in patients with cardiac iron burden, or cardiac complications should be evaluated in patients with diabetes.

Patients with short stature were found prone to cardiac iron overload. In the literature, we found no exact correlation with short stature, and heart iron burden. Short stature can originate from deficiency of growth hormone, lack of growth factors due to liver dysfunction, degenerated bone metabolism, and disease chronicity $[33,34]$. The chronic process of iron overload in hepatic and extrahepatic tissues can affect hormonal regulation, which in turn can cease the increase in height. The limitation of our study is its retrospective design, the restricted number of patients with significantly smaller and younger study cohorts, and lack of a control group.

\section{Conclusion}

In the present study, we found that two out of three patients with thalassemia had an endocrine complication. The serum ferritin level of patients should be kept below $840 \mathrm{ng} / \mathrm{mL}$ by the administration of appropriate chelation therapy to avoid iron burden in endocrine organs. Patients with cardiac iron burden should be closely followed up in terms of endocrine complications.

\section{Declarations}

\section{Conflict of Interest and Disclosure}

All authors declare that they have no conflict of interest.

\section{Acknowledgement}

We thank to Mr. David Chapman and Istanbul University language editors for kindly revising of our paper in terms of English language. 


\section{References}

1. Cappellini MD, Cohen A, Porter J, Taher A, Viprakasit V. Guidelines for the management of transfusion-dependent thalassaemia (TDT). 3rd ed. Thalassaemia International Federation TIF Publication, 2014; 17-65.

2. Marcon A, Motta I, Taher AT, Cappellini MD. Clinical Complications and Their Management. Hematol Oncol Clin North Am. 2018;32(2):223-36.

3. De Sanctis V, Roos M, Gasser T, Fortini M, Raiola G, Galati MC, Italian Working Group on Endocrine Complications in Non-Endocrine Diseases. Impact of long-term iron chelation therapy on growth and endocrine functions in thalassaemia. J PediatrEndocrinolMetab. 2006;19:471-80.

4. Oudit GY, Trivieri MG, Khaper N, Liu PP, Backx PH. Role of L-type Ca2_ channels in iron transport and iron-overload cardiomyopathy. J Mol Med. 2006;84(5):349-64.

5. Jensen PD, Jensen FT, Christensen T, Eiskjaer H, Baandrup U, Nielsen JL. Evaluation of myocardial iron by magnetic resonance imaging during iron chelation therapy with deferrioxamine: indication of close relation between myocardial iron content and chelatable iron pool. Blood. 2003;101(11):46329.

6. Noetzli LJ, Papudesi J, Coates TD, Wood JC. Pancreatic iron loading predicts cardiac iron loading in thalassemia major. Blood. 2009;114(19):4021-6.

7. Mokhtar GM, Ibrahim WE, Elbarbary NS, Matter RM, Ibrahim AS, Sayed SM. Pancreatic functions in adolescents with beta thalassemia major could predict cardiac and hepatic iron loading: relation to T2-star (T2*) magnetic resonance imaging. J Investig Med. 2016;64(3):771-81.

8. Wood JC. Impact of iron assessment by MRI. Hematol Am Soc Hematol Educ Program 2011:443450.

9. Perifanis V, Christoforidis A, Vlachaki E, et al. Comparison of effects of different long-term ironchelation regimens on myocardial and hepatic iron concentrations assessed with $\mathrm{T} 2{ }^{*}$ magnetic resonance imaging in patients with beta-thalassemia major. Int J Hematol. 2007;86(5):385-9.

10. Au W-Y, Lam W-M, Chu W, et al. A T2* magnetic resonance imaging study of pancreatic iron overload in thalassemia major. Haematologica. 2008;93(1):116-9.

11. Restaino G, Meloni A, Positano V, et al. Regional and global pancreatic T*2 MRI for iron overload assessment in a large cohort of healthy subjects: normal values and correlation with age and gender. MagnReson Med. 2011;65(3):764-9.

12. Meloni A, Restaino G, Missere $M$, et al. Pancreatic iron overload by $T 2{ }^{\star} M R I$ in a large cohort of well treated thalassemia major patients: can it tell us heart iron distribution and function? Am J Hematol. 2015;90(9):E189-90.

13. deAssis RA, Ribeiro AA, Kay FU, Rosemberg LA, Nomura CH, Loggetto SR, et al. Pancreatic iron stores assessed by magnetic resonance imaging (MRI) in beta thalassemic patients. Eur J Radiol. 2012;81(7):1465-70. 
14. Sirlin CB, Reeder SB. Magnetic resonance imaging quantification of liver iron. Magn Reson Imaging Clin N Am. 2010;18(3):359-81.

15. De Sanctis V, Soliman AT, Elsedfy H, Skordis N, Kattamis C, Angastiniotis M, et al. Growth and endocrine disorders in thalassemia: The international network on endocrine complications in Thalassemia (I-CET) position statement and guidelines. Indian J Endocrinol Met. 2013;17(1):8-18.

16. De Sanctis V, Eleftheriou A, Malaventura C. Thalassaemia International Federation Study Group on Growth and Endocrine Complications in Thalassaemia. Prevalence of endocrine complications and short tature in patients with thalassaemia major: a multicenter study by the Thalassaemia International Federation (TIF). Pediatr Endocrinol Rev. 2004;2:249-55.

17. Borgna-Pignatti C, Cappellini MD, De Stefano P, Del Vecchio GC, Forni GL, Gamberini MR, Ghilardi R, et al. Survival complications in Thalassemia MajorAnnN Y AcadSci. 2005;1054:40-7.

18. Li CK, Luk CW, Ling SC, Chik KW, Yuen HL, Shing MM. etal.Morbidity and mortality patterns of thalassaemia major patients in Hong Kong: retrospective study.Hong Kong. Med J. 2002;8:255-60.

19. Isik P, Yarali N, Tavil B, Demirel F, Karacam GB, Sac RU, et al. Endocrinopathies in Turkish children with Beta thalassemia major: Results from a single center study. Pediatr Hematol Oncol. 2014;31:607-15.

20. Altincik A, Akin M. Prevalence of endocrinopathies in Turkish children with $\beta$-thalassemia major: A single-center study. J Pediatr Hematol Oncol. 2016;38(5):389-93.

21. Bronspiegel-Weintrob N, Olivieri NF, Tyler B, Andrews DF, Freedman MH, Holland FJ. Effect of age at the start of iron chelation therapy on gonadal function in beta-thalassemia major.N Engl. $\mathrm{J}$ Med. 1990;323(11):713-9.

22. Gamberini MR, De Sanctis V, Gilli G. Hypogonadism, diabetes mellitus, hypothyroidism, hypoparathyroidism: incidence and prevalence related to iron overload and chelation therapy in patients with thalassaemia major followed from 1980 to 2007 in the Ferrara Centre.PediatrEndocrinol Rev. 2008;6Suppl 1:158-69.

23. Bilgin BK, Yozgat AK, Isik $P$, et al. The effect of deferasirox on endocrine complications in children with thalassemia. Pediatr Hematol Oncol. 2020;1-10.

24. Kolnagou A, Natsiopoulos K, Kleanthous M, loannou A, Kontoghiorghes GJ. Liver iron and serum ferritin levels are misleading for estimating cardiac, pancreatic, splenic and total body iron load in thalassemia patients: factors influencing the heterogenic distribution of excess storage iron in organs as identified by MRI T2*.ToxicolMech. Methods. 2013;23(1):48-56.

25. Simcox JA, McClain DA. Iron and diabetes risk. Cell Metab. 2013;17(3):329-41.

26. Tzoulis $P$, Shah F, Jones $R$, et al. Joint diabetes thalassaemia clinic: an effective new model of care. Hemoglobin. 2014;38:104-10.

27. Tzoulis P. Review of Endocrine Complications in Adult Patients With $\beta$-Thalassaemia Major. Thalassemia Reports. 2014;4:4871.

28. Fernandes JL. MRI for iron overload in thalassemia. Hematol Oncol Clin North Am. 2018;32(2):27795. 
29. Barrera CA, Otero HJ, Hartung HD, Biko DM, Serai SD. Protocol optimization for cardiac and liver iron content assessment using MRI: What sequence should I use? Clin Imaging. 2019;56:52-7.

30. Sheth $S$, Allen CJ, Farrell DE, et al. Measurement of the liver iron concentration in transfusional iron overload by MRI R2* and by high-transition-temperature superconducting magnetic susceptometry. Clin Imaging. 2019;55:65-70.

31. Tanner MA, Galanello R, Dessi C, Smith GC, Westwood MA, Agus A, Roughton M, Assomull R, Nair SV, Walker JM. Pennell DJ.A randomized, placebo-controlled, double-blind trial of the effect of combined therapy with deferoxamine and deferiprone on myocardial iron in thalassemia major using cardiovascular magnetic resonance.Circulation. 2007;115(14):1876-84.

32. Pepe A, Meloni A, Rossi G, Caruso V, Cuccia L, Spasiano A, et al. Cardiac complications and diabetes in thalassaemia major: a large historical multicentre study. Br J Haematol. 2013;163(4):520-7.

33. Kyriakou A, Skordis N. Thalassaemia and aberrations of growth and puberty. Mediterr J Hematol Infect Dis. 2009;1(1):e2009003.

34. Soliman AT, Khalafallah H, Ashour R. Growth and factors affecting it in thalassemia major. Hemoglobin. 2009;33(Suppl 1):116-26.

35. Soliman AT, Khalafallah H, Ashour R. Growth and factors affecting it in thalassemia major. Hemoglobin. 2009;33(Suppl 1):116-26.

36. Pennell DJ, Udelson JE, Arai AE, Bozkurt B, Cohen AR, Galanello R, et al, American Heart Association Committee on Heart Failure and Transplantation of the Council on Clinical Cardiology and Council on Cardiovascular Radiology and Imaging. Cardiovascular function and treatment in $\beta$-thalassemia major: a consensus statement from the American Heart Association. Circulation. 2013;128(3):281308.

37. Pepe A, Meloni A, Pistoia L, Cuccia L, Gamberini MR, Lisi R, et al. MRI multicentre prospective survey in thalassaemia major patients treated with deferasirox versus deferiprone and desferrioxamine. $\mathrm{Br} J$ Haematol. 2018;183(5):783-95.

38. Pepe A, Pistoia L, Gamberini MR, Cuccia L, Peluso A, Messina G, Spasiano A, et al. The Close Link of Pancreatic Iron With Glucose Metabolism and With Cardiac Complications in Thalassemia Major: A Large, Multicenter Observational Study. Diabetes Care. 2020;43(11):2830-9.

39. Pacifico L, Martino MD, Catalano C, Panebianco V, Bezzi M, Anania C, et al. T1-weighted dual-echo MRI for fat quantification in pediatric nonalcoholic fatty liver disease. World J Gastroenterol. 2011;17(25):3012-9.

\section{Figures}




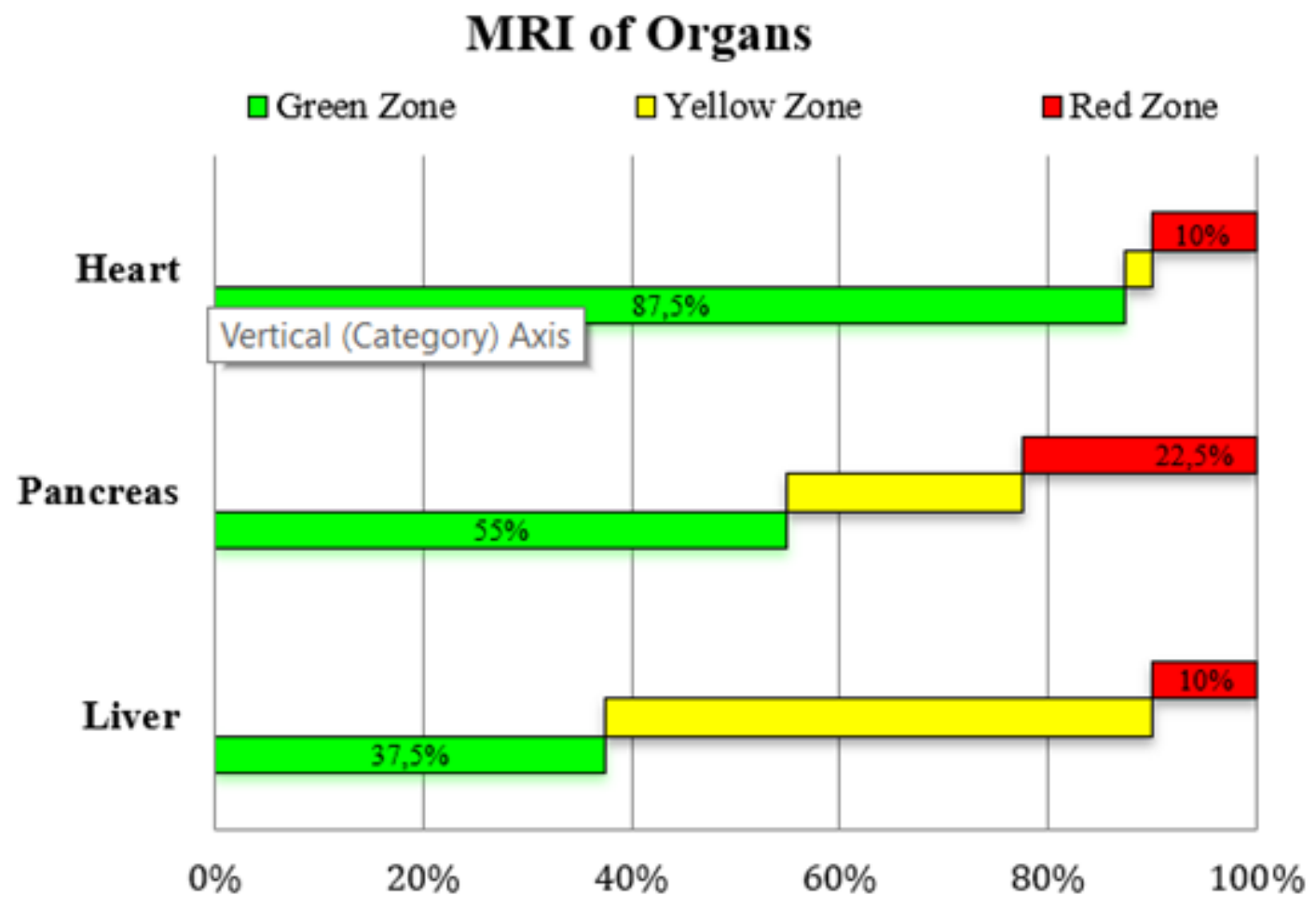

MRI values in organs; green zone, yellow zone and red zone respectively:

Heart T2* $>20 ; 10-20 ;<10 \mathrm{~ms}$; Pancreas R2*<48; 48-150; $>150 \mathrm{~Hz}$ and Liver T2* $>6.7 ; 1.4-6.7 ;<1.4 \mathrm{~ms}$

\section{Figure 1}

Severity of iron burden of organs in participants 